\title{
Sivelestat sodium hydrate improves post-traumatic knee osteoarthritis through nuclear factor- $\kappa B$ in a rat model
}

\author{
XIAOFENG YU ${ }^{1}$, LIJUN ZHAO ${ }^{2}$, ZHIPING YU ${ }^{1}$, CHANGZHENG YU ${ }^{1}$, JIANFEI BI $^{1}$, \\ BINGLONG SUN ${ }^{1}$ and HAIBO CONG ${ }^{1}$
}

Departments of ${ }^{1}$ Joint Surgery and ${ }^{2}$ Operating Theatre, Weihai Central Hospital, Weihai, Shandong 264400, P.R. China

Received November 2, 2015; Accepted March 10, 2017

DOI: $10.3892 /$ etm.2017.4684

\begin{abstract}
As a specific inhibitor of neutrophil elastase, sivelestat sodium hydrate has primarily been used in the treatment of acute lung injury caused by various factors since its approval in 2002. Sivelestat sodium hydrate also improves post-traumatic knee osteoarthritis (KOA), although its underlying mechanisms of action have yet to be elucidated. The aim of the current study was to determine if sivelestat sodium hydrate improves post-traumatic KOA through nuclear factor $(\mathrm{NF})-\kappa \mathrm{B}$ in a rat model. Treatment with sivelestat sodium hydrate significantly inhibited the induction of structural changes and significantly increased the vertical episode count and ipsilateral static weight bearing of the joint in KOA rats (all $\mathrm{P}<0.01$ ). Sivelestat sodium hydrate significantly inhibited tumor necrosis factor- $\alpha$ and interleukin- 6 production, serum nitrite levels, inducible nitric oxide synthase protein expression and high mobility group box 1 (HMGB1) secretion in KOA rats compared with the model group (all $\mathrm{P}<0.01$ ). Sivelestat sodium hydrate also significantly suppressed p50/p65 DNA binding activity and $\mathrm{NF}-\kappa \mathrm{B}$ and phosphorylated inhibitor of $\kappa \mathrm{B}$ protein expression in the joints of KOA rats compared with the model group (all $\mathrm{P}<0.01$ ). These results suggest that sivelestat sodium hydrate improves post-traumatic KOA through HMGB1 and $\mathrm{NF}-\kappa \mathrm{B}$ in rats.
\end{abstract}

\section{Introduction}

Knee osteoarthritis (KOA), also known as degenerative osteoarthropathy, is a group of heterogeneous diseases caused by integrity failure of articular cartilage and lesions of the subchondral bone plate of articular cartilage (1,2). According to the joint distribution, KOA can be divided into local KOA

Correspondence to: Dr Lijun Zhao, Department of Operating Theatre, Weihai Central Hospital, 3 West of Meter Hill Road, Weihai, Shandong 264400, P.R. China

E-mail: youhao98301@126.com

Key words: sivelestat sodium hydrate, post-traumatic knee osteoarthritis and general KOA. KOA is characterized by joint pain, joint stiffness, limitation of motion and is caused by friction noise of joint motion (3). This disease is mostly found in middle-aged people and its incidence increases with age (4), posing a threat to the health and quality of life of middle-aged and elderly people. The pathogenesis of KOA has not been fully elucidated, but it is generally believed that KOA is primarily caused by biomechanical and genetic factors, as well as exogenous factors, including traumatism, bacterial infection or gene mutation, which cause changes in the metabolism of the synovial membrane, cartilage and bone and generate inflammation and structural damage $(5,6)$.

Risk factors of KOA include being female, increased age, obesity, a genetic history of KOA and trauma. However, the specific pathogenesis remains unclear. It has previously been reported that adipocytokines secreted by adipocytes and inflammatory factors serve an important role in the development of KOA (7). Previous studies have found that KOA can increase the production of pro-inflammatory cytokines and adipocytokines, including interleukin (IL)-6, IL-17, tumor necrosis factor (TNF)- $\alpha$ and other inflammatory cytokines $(8,9)$. It has also been reported that the occurrence of KOA is not a simple degenerative change of articular cartilage involving non-inflammatory factors: Obesity-induced metabolic inflammation and inflammatory cytokines serve a key role in the pathogenesis of KOA (10).

Nuclear factor $(\mathrm{NF})-\kappa \mathrm{B}$ is a protein complex that can bind specifically to the immunoglobulin K-chain gene enhancer sequence (11). As the central transcription factor of inflammation and immune reactions, $\mathrm{NF}-\kappa \mathrm{B}$ can be activated by IL-1, TNF- $\alpha$ and other cytokines and quickly induces the expression of multiple genes through a series of reactions that mainly involve cytokines, inflammatory enzymes and matrix metalloproteinases (12). It has been indicated that the signal transduction pathway of NF- $\kappa \mathrm{B}$ in chondrocytes is activated in a rat model of osteoarthritis (13).

Sivelestat sodium hydrate is a specific inhibitor of neutrophil elastase that was approved for use in Japan in 2002 and is clinically used for patients with acute lung injury accompanied by systematic systemic inflammatory response syndrome (14). However, previous studies have indicated that sivelestat sodium hydrate can also protect the heart, lung, liver, kidney, nerve tissue, spinal cord tissue and other organs from functional injury $(15,16)$. The goal of the current study was to investigate 
whether sivelestat sodium hydrate improves post-traumatic KOA through NF- $\mathrm{kB}$ in a rat model.

\section{Materials and methods}

Animals and studydesign. Ten-week-old male Sprague-Dawley rats (300-325 g; 10-12 weeks old; $\mathrm{n}=30$ ) were caged in pairs in a ventilated animal room at a controlled temperature $\left(20-25^{\circ} \mathrm{C}\right)$ and humidity (40-60\%), with a $12 \mathrm{~h}$ light/dark cycle. They were provided with food and water ad libitum. Rats were randomized into three groups ( $\mathrm{n}=8$ per group): A sham group, KOA model group and sivelestat sodium hydrate (ONO-5046) group. Rats from the sham group received normal saline $(500 \mu \mathrm{l})$ via intraperitoneal (ip) injection. KOA model rats from the model group received normal saline (ip). KOA model rats from the ONO-5046 group received $10 \mathrm{mg} / \mathrm{kg} /$ once weekly ONO-5046 (ip; Sigma-Aldrich; Merck kGaA, Darmstadt, Germany) for 4 weeks. Ethical approval was received from the Medical Ethics Committee of Weihai Central Hospital (Weihai, China).

Study design. In order to establish a KOA model, rat was anesthetized using $35 \mathrm{mg} / \mathrm{kg}$ pentobarbital (Sigma-Aldrich) the right medial meniscotibial ligaments were cut and attention was paid not to injure the articular cartilage during the procedure, as previously described (2). Post-operation, animals were allowed unrestricted activity, ad libitum access to food and water, and housed were under standard conditions $\left(20-25^{\circ} \mathrm{C}\right.$ and $40-60 \%$ humidity). The right hind knee joints from the sham group were sham-operated using the same approach without inducing medial meniscotibial ligament injury.

Analysis of structural joint changes. After rats were anesthetized using $35 \mathrm{mg} / \mathrm{kg}$ pentobarbital (Sigma-Aldrich; Merck KGgA), rats were sacrificed via decollation, the limbs $(0.5 \mathrm{~cm})$ were harvested from all three groups, washed with PBS, and embedded in paraffin following fixation for $72 \mathrm{~h}$ using $4 \%$ paraformaldehyde at room temperature and decalcification using $10 \%$ formaldehyde. Right knee joints were cut into serial frontal sections (5- $\mu \mathrm{M}$ thick) and stained using $0.04 \%$ toluidine blue from six different depths spanning $0.4 \mu \mathrm{m}$ of the joint. Structural joint changes were assessed using the Osteoarthritis Research Society International for cartilage degeneration score (17).

General exploratory motor behavior. Each rat underwent an open field test (AccuScan Instruments, Omnitech Electronics, Inc., Columbus, OH, USA) in a transparent Plexiglas cage (height, $33 \mathrm{~cm}$; width, $42 \mathrm{~cm}$; length, $42 \mathrm{~cm}$ ) for $30 \mathrm{~min}$. This assessment was done after sivelestat sodium hydrate or control treatment. A total of 18 different variables of exploratory motor behavior were assessed, including frequency and duration of horizontal, sedentary, stereotypic, revolution movement and vertical activities. Vertical episode count was one of 18 variables used to assess dynamic pain-related behavior.

Static weight bearing. In a conventional restrainer and separate transducers, rats were habituated to a relatively static position and the average weight on each hindlimb over $5 \mathrm{sec}$ was recorded for five trials. Between the left (contralateral control) and right (ipsilateral) hindlimbs, changes in the hind paw weight bearing distribution were utilized as an index of joint pain-like symptoms in the knees that had undergone surgery. KOA pain and percentage of ipsilateral weight bearing was subsequently calculated as weight on the ipsilateral hind limb divided by weight on both hind limbs multiplied.

Determination of TNF- $\alpha$ and IL-6 production, high mobility group box 1 (HMGB1) secretion and nitrite/nitrate DNA binding activity of $N F-\kappa B$ p50/p65. Blood was collected at 4 weeks after treatment with sivelestat sodium hydrate while rats were under anesthesia $(35 \mathrm{mg} / \mathrm{kg}$ pentobarbital) and centrifuged at $12,000 \mathrm{xg}$ for $10 \mathrm{~min}$ at $4^{\circ} \mathrm{C}$. The supernatant was collected and used to determine the levels of TNF- $\alpha$ (EM010-96) and IL-6 (EM004-96) production and using commercial enzyme-linked immunosorbent assay (ELISA; ExCell Bio, Taichang, China) kits and an ELISA reader (Bio-Rad Laboratories, Inc.) at $405 \mathrm{~nm}$. Nitrite concentrations were measured using a commercial kit (A038; Nanjing Jiancheng Biology Engineering Institute, Nanjing, China) and an ELISA reader (Bio-Rad Laboratories, Inc.) at $540 \mathrm{~nm}$. HMGB1 secretion were measured using a commercial kit (E-EL-R0505c; Elabscience Biotechnology Co., Ltd., Wuhan, China) at $450 \mathrm{nM}$.

Western blot analysis. Arthrosis tissue samples were collected at 4 weeks after treatment with sivelestat sodium hydrate and homogenized using a radioimmunoprecipitation assay lysis buffer (Beyotime Institute of Biotechnology, Nanjing China). The supernatant was collected following centrifugation at $12,000 \mathrm{x}$ g for $10 \mathrm{~min}$ at $4^{\circ} \mathrm{C}$ and protein concentration was determined using BCA assay (Beyotime Institute of Biotechnology, Nanjing China). Proteins (50 $\mu \mathrm{g})$ were separated on a $10 \%$ SDS polyacrylamide gel and transferred to a polyvinylidene difluoride membrane. The membranes were incubated overnight at $4{ }^{\circ} \mathrm{C}$ with anti-inducible nitric oxide synthase (iNOS; sc-8309; 1:500), anti-NF-кB (sc-109; 1:500), anti-phosphorylated inhibitor of $\mathrm{\kappa B}$ (p-IkB; sc-7977; $1: 500)$ and anti- $\beta$-actin (sc-7210; $1: 2,000)$ (all from Santa Cruz Biotechnology) following blocking with 5\% skim milk powder at $37^{\circ} \mathrm{C}$ for $1 \mathrm{~h}$. Membranes were then washed twice with TBS with $0.1 \%$ Tween-20 and incubated for $1 \mathrm{~h}$ with peroxidase-conjugated secondary antibodies (7074; 1:5,000; Cell Signaling Technology, Inc.) at $37^{\circ} \mathrm{C}$. Protein was measured using Bio-Rad Laboratories 3.0 (Bio-Rad Laboratories, Inc., Hercules, CA, USA).

Statistical analysis. All data are presented as the mean \pm standard error of the mean using SPSS.17.0 (SPSS, Inc., Chicago, IL, USA). Data were analyzed using the Mann-Whitney U test for comparison between two independent groups. $\mathrm{P}<0.05$ was considered to indicate a statistically significant difference.

\section{Results}

Sivelestat sodium hydrate suppresses structural changes of the joint in KOA rats. The chemical structure of sivelestat sodium hydrate is presented in Fig. 1. Structural changes of the joint were assessed in the sham, model and ONO-5046 groups (Fig. 2). Cartilage degeneration in the model group 
<smiles></smiles>

Figure 1. The chemical structure of sivelestat sodium hydrate.

was significantly greater than that of the sham group $(\mathrm{P}<0.01)$. However, following 4 weeks treatment, cartilage degeneration was significantly reduced in the ONO-5046 group compared with the model group (both $\mathrm{P}<0.01$; Fig. 2).

Sivelestat sodium hydrate increases vertical episode count in KOA rats. At 4 weeks after treatment, vertical episode count of the joint was significantly lower in the model group compared with the sham group $(\mathrm{P}<0.01)$. However, treatment with sivelestat sodium hydrate significantly increased the vertical episode count in KOA rats compared with the model group $(\mathrm{P}<0.01$; Fig. 3).

Sivelestat sodium hydrate increases ipsilateral static weight bearing of the joint in KOA rats. At 4 weeks after treatment, ipsilateral static weight bearing of the joint was significantly reduced in the KOA model group rats compared with the sham group $(\mathrm{P}<0.01)$. Treatment with sivelestat sodium hydrate significantly increased the ipsilateral static weight bearing of the joint compared with the model group ( $\mathrm{P}<0.01$; Fig. 4).

Sivelestat sodium hydrate suppresses TNF- $\alpha$ and IL-6 production in the joint of KOA rats. To investigate whether sivelestat sodium hydrate affects inflammation in KOA rats,
A

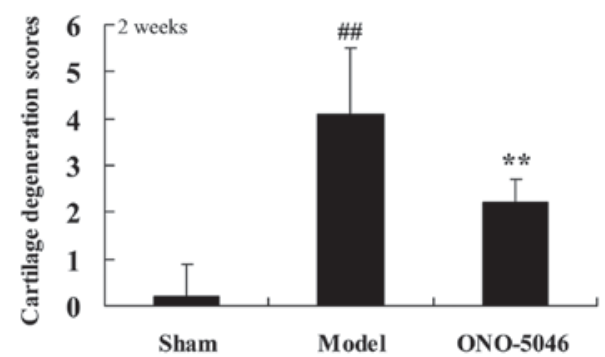

B

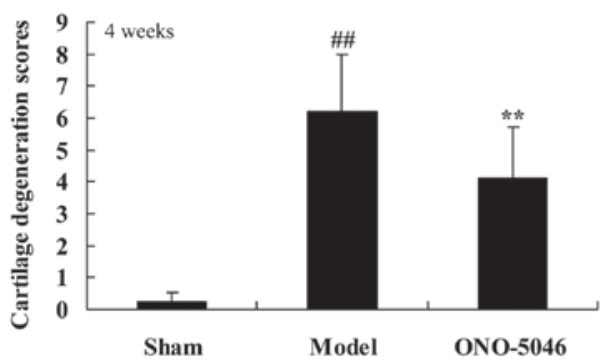

Figure 2. Effect of sivelestat sodium hydrate on structural changes of the joint in rats with post-traumatic knee osteoarthritis. Cartilage degeneration was evaluated at (A) 2 weeks and (B) 4 weeks after treatment. Data are presented as the mean \pm standard error of the mean. ${ }^{\# \#} \mathrm{P}<0.01 \mathrm{vs}$. sham group, ${ }^{* * *} \mathrm{P}<0.01 \mathrm{vs}$. model group. ONO-5046, sivelestat sodium hydrate.
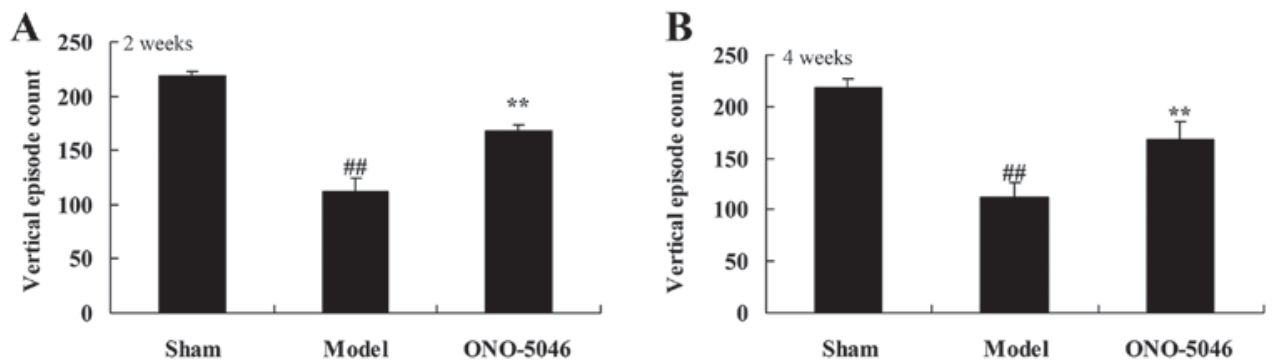

Figure 3. Effect of sivelestat sodium hydrate on vertical episode count in rats with post-traumatic knee osteoarthritis. Vertical episode count was evaluated at (A) 2 weeks and (B) 4 weeks after treatment. Data are presented as the mean \pm standard error of the mean. ${ }^{\# \#} \mathrm{P}<0.01$ vs. sham group, ${ }^{* *} \mathrm{P}<0.01$ vs. model group. ONO-5046, sivelestat sodium hydrate group.

A

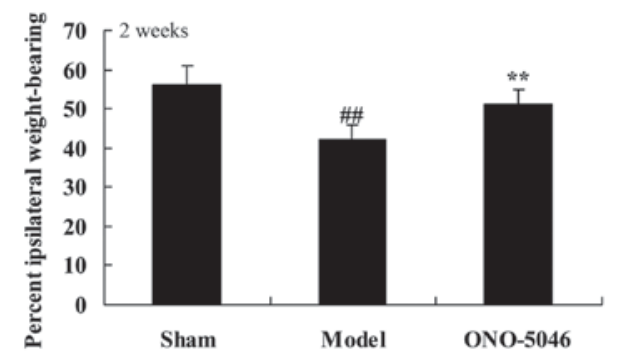

B

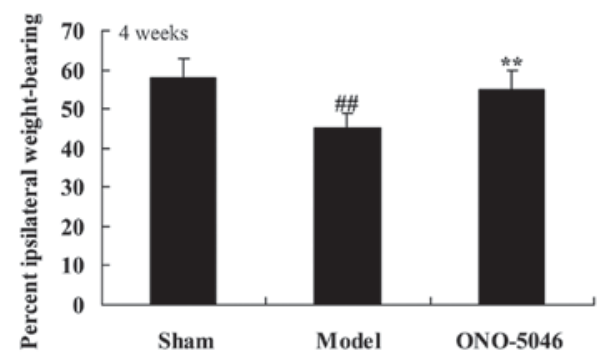

Figure 4. Effect of sivelestat sodium hydrate on ipsilateral static weight bearing of the joint in rats with post-traumatic knee osteoarthritis. Ipsilateral static weight bearing was evaluated at (A) 2 weeks and (B) 4 weeks after treatment. Data are presented as the mean \pm standard error of the mean. ${ }^{\# \#} \mathrm{P}<0.01 \mathrm{vs}$. sham group, ${ }^{* *} \mathrm{P}<0.01$ vs. model group. ONO-5046, sivelestat sodium hydrate group. 

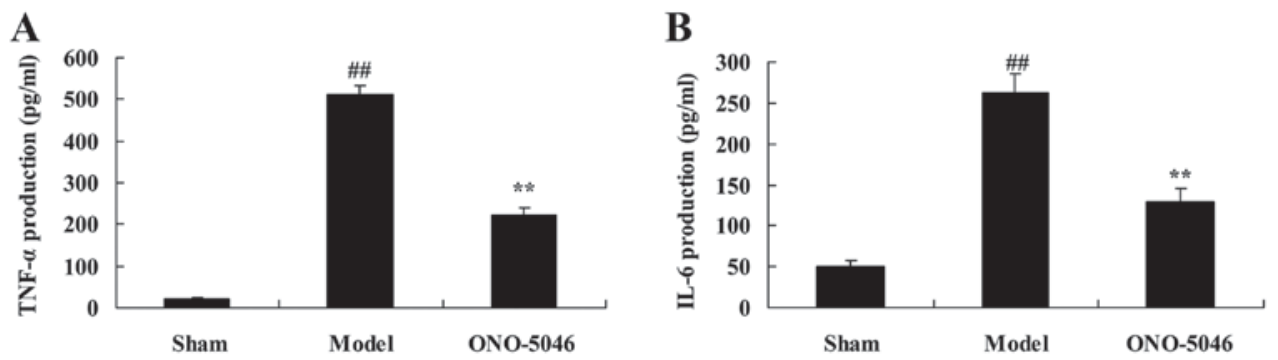

Figure 5. Effect of sivelestat sodium hydrate on TNF- $\alpha$ and IL-6 production in the joints of rats with post-traumatic knee osteoarthritis. (A) TNF- $\alpha$ and (B) IL-6 levels were evaluated by ELISA. Data are presented as the mean \pm standard error of the mean. ${ }^{\# \#} \mathrm{P}<0.01$ vs. sham group, ${ }^{* * *} \mathrm{P}<0.01$ vs. model group. ONO-5046, sivelestat sodium hydrate group; TNF- $\alpha$, tumor necrosis factor- $\alpha$; IL-6, interleukin-6.
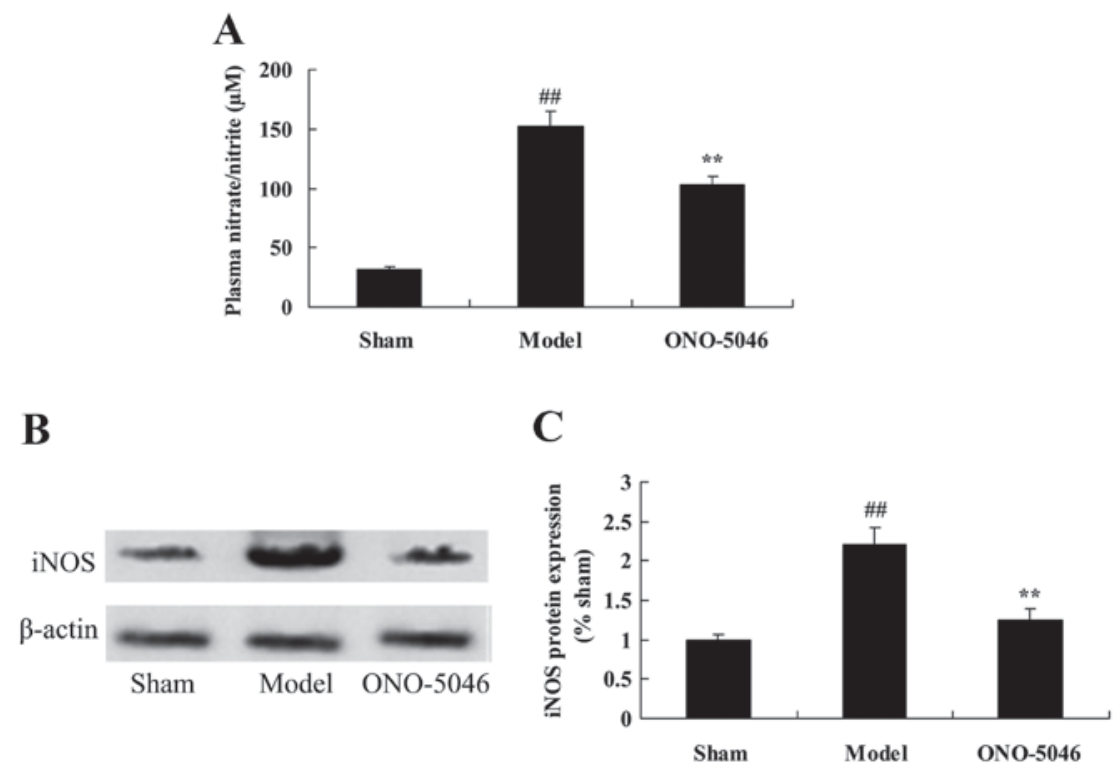

Figure 6. Effect of sivelestat sodium hydrate on serum nitrite levels and iNOS protein expression in the joints of rats with post-traumatic knee osteoarthritis. (A) Serum nitrite levels were evaluated by ELISA. (B and C) Level of iNOS protein expression was evaluated using western blotting. Data are presented as the mean \pm standard error of the mean. ${ }^{\# \#} \mathrm{P}<0.01$ vs. sham group, ${ }^{* *} \mathrm{P}<0.01$ vs. model group. ONO-5046, sivelestat sodium hydrate group; iNOS, inducible nitric oxide synthase.

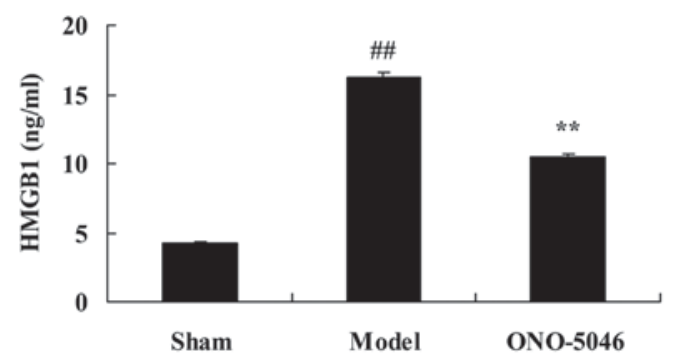

Figure 7. Effect of sivelestat sodium hydrate on HMGB1 secretion in the joints of rats with post-traumatic knee osteoarthritis. HMGB1 level was evaluated by ELISA. Data are presented as the mean \pm standard error of the mean. ${ }^{\# \#} \mathrm{P}<0.01$ vs. sham group, ${ }^{* *} \mathrm{P}<0.01$ vs. model group. ONO-5046, sivelestat sodium hydrate group; HMGB1, high mobility group box 1 .

TNF- $\alpha$ and IL- 6 production was measured by ELISA. There was a significant increase in both TNF- $\alpha$ and IL- 6 production in the model group compared with the sham control group $(\mathrm{P}<0.01)$. However, administration of sivelestat sodium hydrate significantly inhibited TNF- $\alpha$ and IL- 6 production compared with KOA model rats $(\mathrm{P}<0.01$; Fig. 5).
Sivelestat sodium hydrate suppresses serum nitrite levels and iNOS protein expression in the joints of KOA rats. The effect of sivelestat sodium hydrate on serum nitrite levels and iNOS protein expression in the joints of KOA rats was analyzed using ELISA and western blotting, respectively. Serum nitrite levels and iNOS protein expression in KOA model rats were significantly higher compared with the sham group (both $\mathrm{P}<0.01$ ). However, sivelestat sodium hydrate administration significantly reduced the serum nitrite level and iNOS protein expression, compared with the model group (both $\mathrm{P}<0.01$; Fig. 6).

Sivelestat sodium hydrate suppresses HMGB1 secretion in the joints of KOA rats. To investigate the effect of sivelestat sodium hydrate on HMGB1 secretion in the joints of KOA rats, HMGB1 secretion was detected by ELISA. There was a significant increase in HMGB1 secretion in the model group as compared with the sham group $(\mathrm{P}<0.01)$. Following treatment with sivelestat sodium hydrate, HMGB1 secretion was significantly suppressed compared with the model group $(\mathrm{P}<0.01$; Fig. 7). 


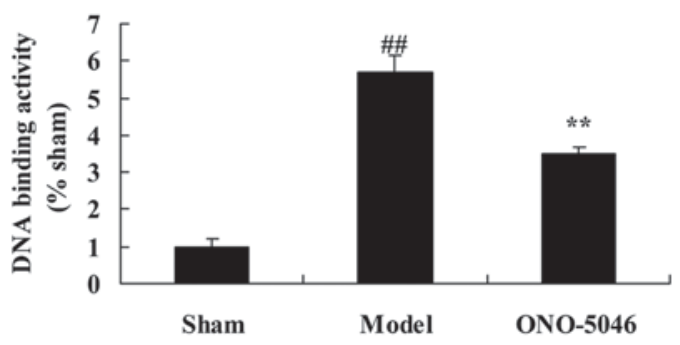

Figure 8 . Effect of sivelestat sodium hydrate on DNA binding activity in the joints of rats with post-traumatic knee osteoarthritis. DNA binding activity was evaluated by ELISA. Data are presented as the mean \pm standard error of the mean. ${ }^{\# \prime} \mathrm{P}<0.01$ vs. sham group, ${ }^{* *} \mathrm{P}<0.01$ vs. model group. ONO-5046, sivelestat sodium hydrate group.

Sivelestat sodium hydrate suppresses p50/p65 DNA binding activity in the joints of KOA rats. To investigate the effect of sivelestat sodium hydrate on p50/p65 DNA binding activity in the joints of KOA rats, p50/p65 DNA binding activity was evaluated by ELISA. The level of p50/p65 DNA binding activity was significantly increased in the model group compared with the sham group $(\mathrm{P}<0.01)$. By contrast, p50/p65 DNA binding activity in KOA rats treated with sivelestat sodium hydrate was significantly inhibited, compared with the model group (P<0.01; Fig. 8).

Sivelestat sodium hydrate suppresses $N F-\kappa B$ protein expression in the joints of KOA rats. To examine the anti-inflammation effect of sivelestat sodium hydrate on KOA, NF- $\mathrm{KB}$ protein expression was analyzed using western blotting. NF- $\kappa \mathrm{B}$ protein expression was significantly increased in the model group compared with the sham group $(\mathrm{P}<0.01)$. However, treatment with sivelestat sodium hydrate significantly reduced KOA-induced NF- $\kappa B$ protein expression in KOA rats compared with the model group $(\mathrm{P}<0.01$; Fig. 9$)$.

Sivelestat sodium hydrate suppresses $p$-I $\kappa B$ protein expression in the joints of KOA rats. To further analyze the anti-inflammation effect of sivelestat sodium hydrate on NF- $\kappa \mathrm{B}, \mathrm{p}-\mathrm{I} \kappa \mathrm{B}$ protein expression was detected using western blotting. The results indicated that $\mathrm{p}$-IкB protein expression was significantly higher in the model group compared with the sham group $(\mathrm{P}<0.01)$. Following sivelestat sodium hydrate treatment, $\mathrm{p}-\mathrm{I} \kappa \mathrm{B}$ protein expression in KOA rats was significantly suppressed compared with the model group $(\mathrm{P}<0.01$; Fig. 10).

\section{Discussion}

KOA is a degenerative disease characterized by the progressive loss of cartilage accompanied by subchondral bone destruction, marginal osteophyte formation and joint space narrowing (18). According estimates from the World Health Organization, the prevalence of symptomatic KOA among people $>60$ years old worldwide is $9.6 \%$ for males and $18 \%$ for females, and the disability rate may be as high as $53 \%$ (19). KOA tends to develop in joints that undergo heavy weight bearing and continuous activity (20). The results of the current study indicated that treatment with sivelestat sodium hydrate
A

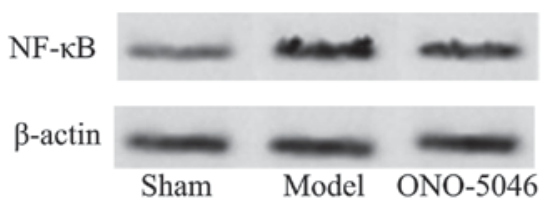

B

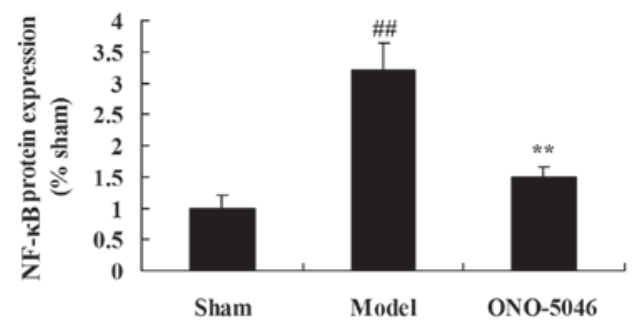

Figure 9. Effect of sivelestat sodium hydrate on NF- $\mathrm{B}$ protein expression in the joints of rats with post-traumatic knee osteoarthritis. NF- $\kappa \mathrm{B}$ protein expression was evaluated using (A) western blotting and the data were (B) quantified. Data are presented as the mean \pm standard error of the mean. ${ }^{\# \# ~} \mathrm{P}<0.01 \mathrm{vs}$. sham group, ${ }^{* *} \mathrm{P}<0.01$ vs. model group. ONO-5046, sivelestat sodium hydrate group; $\mathrm{NF}-\kappa \mathrm{B}$, nuclear factor- $\kappa \mathrm{B}$.

A

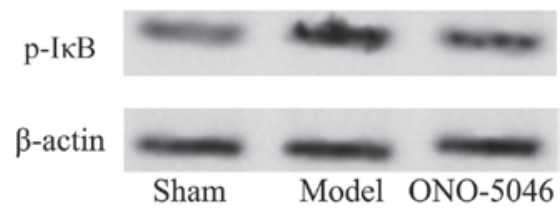

B

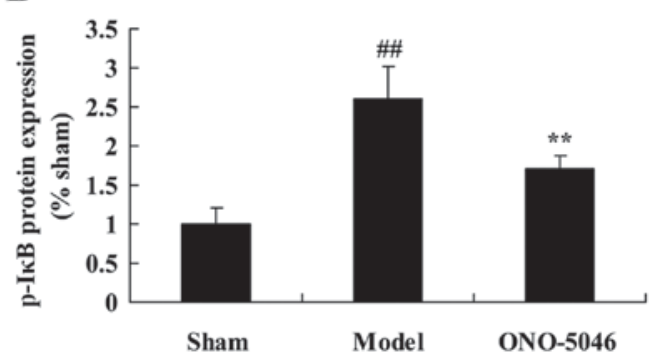

Figure 10. Effect of sivelestat sodium hydrate on $\mathrm{p}-\mathrm{I} \kappa \mathrm{B}$ protein expression in the joints of rats with post-traumatic knee osteoarthritis. p-I $\mathrm{B}$ protein expression was evaluated using (A) western blotting and these data were (B) quantified. Data are presented as the mean \pm standard error of the mean. ${ }^{\# \#} \mathrm{P}<0.01$ vs. sham group, ${ }^{* *} \mathrm{P}<0.01$ vs. model group. ONO-5046, sivelestat sodium hydrate group; $\mathrm{p}-\mathrm{I} \kappa \mathrm{B}$, phosphorylated inhibitor of $\kappa \mathrm{B}$. 
significantly inhibits the induction of structural changes, increases vertical episode count and increases ipsilateral static weight bearing of the joint in KOA rats.

KOA-related cytokines include the inflammatory cytokines, which mediate matrix damage and inhibit the proliferation of chondrocytes, such as IL-1 $\beta$, TNF- $\alpha$ and nitric oxide (NO) (21). IL-1 serves an important role in the pathogenesis of $\mathrm{KOA}$; it is one of the most influential cytokines leading to the functional decline of cartilage (22). IL-1 $\beta$ and IL-6 also has a wide range of biological effects that may act on a localized area or affect the whole body, and it is involved in inflammatory reactions (23). In acute and chronic inflammation, IL-1 may cause systemic symptoms, such as fever, muscle consumption and the synthesis of proteins in the acute phase, and local tissue inflammation and destructive lesions (24). In the current study, it was demonstrated that administration of sivelestat sodium hydrate in rats with KOA significantly inhibited TNF- $\alpha$ and IL- 6 production compared with model rats. Yoshikawa et al (25) reported that sivelestat sodium hydrate reduced radiation-induced lung injury in mice by inhibiting neutrophil elastase activity and excessive inflammatory reactions. Therefore, sivelestat sodium hydrate improves post-traumatic KOA and may also have anti-inflammatory properties.

At present, the pathogenesis of KOA remains unclear, but it has been confirmed that NO serves an important role in the development of KOA (26). NO is an important regulatory factor involved in the differentiation and apoptosis of articular cartilage cells (27). It can inhibit the proliferation of chondrocytes, induce the apoptosis of chondrocytes, inhibit the synthesis of proteoglycan and type II collagen by chondrocytes and promote the decomposition of cartilage matrix (27). In KOA, iNOS is the key enzyme that induces the production of NO (26). The current data suggests that sivelestat sodium hydrate significantly reduces serum nitrite levels and iNOS protein expression in KOA rats. Hagiwara et al (14) demonstrated that sivelestat sodium hydrate reduces levels of inflammatory mediators by inhibiting NF- $\mathrm{KB}$.

$N F-\kappa B$ is a central transcription factor involved in inflammatory and immune reactions. It usually exists in the cytoplasm in the form of a p50-p65 heterodimer, which is predominantly in an inactivated state, bound to the inhibitory

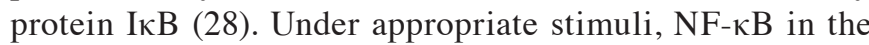
cytoplasm dissociates from IкB and enters the cell nucleus, a process known as nuclear translocation $(29,30)$. NF- $\mathrm{\kappa B}$ can be activated by many factors, including TNFs and ILs. Once in the cell nucleus, activated NF- $\mathrm{\kappa B}$ binds with the specific sequences of the promoter/enhancer regions of target genes and regulates gene expression $(31,32)$. The activated NF- $\mathrm{KB}$ signal transduction pathway may lead to the transcription of a series of downstream target genes, which trigger biological effects including the production of inflammatory factors and the induction of chondrocyte apoptosis (13). The results of the present study also indicated that sivelestat sodium hydrate suppresses p50/p65 DNA binding activity, $\mathrm{NF}-\kappa \mathrm{B}$ and $\mathrm{p}-\mathrm{IkB}$ protein expression in the joints of rats with post-traumatic KOA. This is in accordance with a study by Hagiwara et al (33), which demonstrated that sivelestat sodium hydrate reduces the levels of inflammatory mediators by inhibiting NF- $\mathrm{KB}$.
HMGB1 is a type of alarmin that can activate the innate immunity and acquired immune response and is involved in the development of many diseases (34). Binding between the DNA-binding domain of HMGB1 in the cell nucleus and a minor groove in the double helix can cause DNA structural changes that affect DNA transcription, repair, replication and nucleosome stability (35). Extracellular HMGB1 secretion may promote an inflammatory reaction by binding to the HMGB1 receptor (36). It has previously been demonstrated that extracellular HMGB1 is a potential induction factor of inflammation, and HMGB1 monoclonal antibodies are effective at treating hepatonecrosis caused by septicopyemia, stroke and other conditions $(37,38)$. Furthermore, it has been reported that arthritis can be induced by injecting HMGB1 into rat joints, and that HMGB1-targeted treatment can effectively prevent the development of arthritis in experimental animal models (35). The current findings indicate that treatment with sivelestat sodium hydrate significantly suppresses HMGB1 secretion in KOA rats compared with the model group. In addition, Hagiwara et al (14) reported that sivelestat sodium hydrate reduces lung injury following endotoxin-induced shock through suppression of HMGB1 in rats.

In conclusion, the results of the current study indicate that sivelestat sodium hydrate inhibits the induction of structural changes, increases vertical episode count and ipsilateral static weight bearing of the joint in KOA rats, and may exert an anti-inflammatory effect due to inhibition of HMGB1 and $\mathrm{NF}-\kappa \mathrm{B}$, as well as NO secretion. Further studies will be required to elucidate whether sivelestat sodium hydrate induces an anti-inflammatory effect on KOA or other diseases.

\section{References}

1. Provenza JR, Shinjo SK, Silva JM, Peron CR and Rocha FA: Combined glucosamine and chondroitin sulfate, once or three times daily, provides clinically relevant analgesia in knee osteoarthritis. Clin Rheumatol 34: 1455-1462, 2015.

2. Glasson SS, Blanchet TJ and Morris EA: The surgical destabilization of the medial meniscus (DMM) model of osteoarthritis in the 129/SvEv mouse. Osteoarthritis Cartilage 15: 1061-1069, 2007.

3. Tok F, Aydemir K, Peker F, Safaz I, Taskaynatan MA and Ozgül A: The effects of electrical stimulation combined with continuous passive motion versus isometric exercise on symptoms, functional capacity, quality of life and balance in knee osteoarthritis: Randomized clinical trial. Rheumatol Int 31: 177-181, 2011.

4. Thorp LE, Wimmer MA, Block JA, Moisio KC, Shott S, Goker B and Sumner DR: Bone mineral density in the proximal tibia varies as a function of static alignment and knee adduction angular momentum in individuals with medial knee osteoarthritis. Bone 39: 1116-1122, 2006.

5. Trombini-Souza F, Kimura A, Ribeiro AP, Butugan M, Akashi P, Pássaro AC, Arnone AC and Sacco IC: Inexpensive footwear decreases joint loading in elderly women with knee osteoarthritis. Gait Posture 34: 126-130, 2011.

6. Kobayashi T, Yoshihara Y, Yamada $\mathrm{H}$ and Fujikawa K: Procollagen IIC-peptide as a marker for assessing mechanical risk factors of knee osteoarthritis: Effect of obesity and varus alignment. Ann Rheum Dis 59: 982-984, 2000.

7. Sundman EA, Cole BJ, Karas V, Della Valle C, Tetreault MW, Mohammed HO and Fortier LA: The anti-inflammatory and matrix restorative mechanisms of platelet-rich plasma in osteoarthritis. Am J Sports Med 42: 35-41, 2014.

8. Clockaerts S, Bastiaansen-Jenniskens YM, Feijt C, Verhaar JA, Somville J, De Clerck LS and Van Osch GJ: Peroxisome proliferator activated receptor alpha activation decreases inflammatory and destructive responses in osteoarthritic cartilage. Osteoarthritis Cartilage 19: 895-902, 2011. 
9. Wang S, Liu J, Wu DI, Pang X, Zhao J and Zhang $X$ Pro-inflammatory effect of fibrinogen on vascular smooth muscle cells by regulating the expression of PPAR $\alpha$, PPAR $\gamma$ and MMP-9. Biomed Rep 3: 513-518, 2015.

10. Bevers K, Zweers MC, Vriezekolk JE, Bijlsma JW and den Broeder AA: Are ultrasonographic signs of inflammation predictors for response to intra-articular glucocorticoids in knee osteoarthritis? Clin Exp Rheumatol 32: 930-934, 2014.

11. Shi C,Zhu X, Wang J and Long D: Intromitochondrial $\mathrm{I}_{\kappa} \mathrm{B} / \mathrm{NF}-\kappa \mathrm{B}$ signaling pathway is involved in amyloid $\beta$ peptide-induced mitochondrial dysfunction. J Bioenerg Biomembr 46: 371-376, 2014.

12. Rigoglou S and Papavassiliou AG: The NF- $\mathrm{kB}$ signalling pathway in osteoarthritis. Int J Biochem Cell Biol 45: 2580-2584, 2013.

13. Roman-Blas JA and Jimenez SA: NF-kappaB as a potential therapeutic target in osteoarthritis and rheumatoid arthritis. Osteoarthritis Cartilage 14: 839-848, 2006.

14. Hagiwara S, Iwasaka H, Togo K and Noguchi T: A neutrophil elastase inhibitor, sivelestat, reduces lung injury following endotoxin-induced shock in rats by inhibiting HMGB1. Inflammation 31: 227-234, 2008.

15. Nishiyama J, Matsuda M, Ando S, Hirasawa M, Suzuki T and Makuuchi H: The effects of the early administration of sivelestat sodium, a selective neutrophil elastase inhibitor, on the postoperative course after radical surgery for esophageal cancer. Surg Today 42: 659-665, 2012.

16. Masaoka N, Watanabe $M$ and Nakajima Y: The effects of sivelestat sodium hydrate on uterine contraction and the concentration of maternal and fetal blood cytokines in a sheep model of intra-amniotic infection induced by lipopolysaccharide. J Matern Fetal Neonatal Med 24: 1013-1018, 2011.

17. Hamilton CB, Pest MA, Pitelka V, Ratneswaran A, Beier F and Chesworth BM: Weight-bearing asymmetry and vertical activity differences in a rat model of post-traumatic knee osteoarthritis. Osteoarthritis Cartilage 23: 1178-1185, 2015.

18. Helminen EE, Sinikallio SH, Valjakka AL, Väisänen-Rouvali RH and Arokoski JP: Effectiveness of a cognitive-behavioural group intervention for knee osteoarthritis pain: A randomized controlled trial. Clin Rehabil 29: 868-881, 2015.

19. Bodick N, Lufkin J, Willwerth C, Kumar A, Bolognese J, Schoonmaker C, Ballal R, Hunter D and Clayman M: An intra-articular, extended-release formulation of triamcinolone acetonide prolongs and amplifies analgesic effect in patients with osteoarthritis of the knee: A randomized clinical trial. J Bone Joint Surg Am 97: 877-888, 2015.

20. Bezalel T, Carmeli E and Katz-Leurer M: The effect of a group education programme on pain and function through knowledge acquisition and home-based exercise among patients with knee osteoarthritis: A parallel randomised single-blind clinical trial Physiotherapy 96: 137-143, 2010.

21. Bingham CO III, Sebba AI, Rubin BR, Ruoff GE, Kremer J, Bird S, Smugar SS, Fitzgerald BJ, O'Brien K and Tershakovec AM: Efficacy and safety of etoricoxib $30 \mathrm{mg}$ and celecoxib $200 \mathrm{mg}$ in the treatment of osteoarthritis in two identically designed, randomized, placebo-controlled, non-inferiority studies. Rheumatology (Oxford) 46: 496-507, 2007.

22. Boyer KA, Angst MS, Asay J, Giori NJ and Andriacchi TP: Sensitivity of gait parameters to the effects of anti-inflammatory and opioid treatments in knee osteoarthritis patients. J Orthop Res 30: 1118-1124, 2012.

23. Tian CF, Lv FH, Wang M and Gu XS: Serum $\beta$-human chorionic gonadotropin and interleukin-1 as diagnostic biomarkers for the premature rupture of membranes and chorioamnionitis. Biomed Rep 2: 905-909, 2014.
24. Simao AP, Avelar NC, Tossige-Gomes R, Neves CD, Mendonça VA, Miranda AS, Teixeira MM, Teixeira AL, Andrade AP, Coimbra CC and Lacerda AC: Functional performance and inflammatory cytokines after squat exercises and whole-body vibration in elderly individuals with knee osteoarthritis. Arch Phys Med Rehabil 93: 1692-1700, 2012.

25. Yoshikawa N, Inomata T, Okada Y, Shimbo T, Takahashi M, Akita K, Uesugi Y and Narumi Y: Sivelestat sodium hydrate reduces radiation-induced lung injury in mice by inhibiting neutrophil elastase. Mol Med Rep 7: 1091-1095, 2013.

26. More AS, Kumari RR, Gupta G, Lingaraju MC, Balaganur V, Pathak NN, Kumar D, Kumar D, Sharma AK and Tandan SK: Effect of iNOS inhibitor S-methylisothiourea in monosodium iodoacetate-induced osteoathritic pain: Implication for osteoarthritis therapy. Pharmacol Biochem Behav 103: 764-772, 2013.

27. Jarvinen $K$, Vuolteenaho $K$, Nieminen $R$, Moilanen $T$, Knowles RG and Moilanen E: Selective iNOS inhibitor 1400W enhances anti-catabolic IL-10 and reduces destructive MMP-10 in OA cartilage. Survey of the effects of $1400 \mathrm{~W}$ on inflammatory mediators produced by OA cartilage as detected by protein antibody array. Clin Exp Rheumatol 26: 275-282, 2008.

28. Hu H, Yang B, Li Y, Zhang S and Li Z: Blocking of the P2X7 receptor inhibits the activation of the MMP-13 and NF- $\mathrm{KB}$ pathways in the cartilage tissue of rats with osteoarthritis. Int J Mol Med 38: 1922-1932, 2016.

29. Neurath MF, Becker C and Barbulescu K: Role of NF-kappaB in immune and inflammatory responses in the gut. Gut 43: 856-860, 1998.

30. Yoshikawa H, Kurokawa M, Ozaki N, Nara K, Atou K, Takada E, Kamochi H and Suzuki N: Nicotine inhibits the production of proinflammatory mediators in human monocytes by suppression of I-kappaB phosphorylation and nuclear factor-kappaB transcriptional activity through nicotinic acetylcholine receptor alpha7. Clin Exp Immunol 146: 116-123, 2006.

31. Lee J, Choi J and Kim S: Effective suppression of pro-inflammatory molecules by DHCA via IKK-NF- $\kappa$ B pathway, in vitro and in vivo. Br J Pharmacol 172: 3353-3369, 2015.

32. Cheng CC, Chen YH, Chang WL, Yang SP, Chang DM, Lai JH and HoLJ: Phytoestrogen bavachin mediates anti-inflammation targeting Ikappa B kinase-I kappaB alpha-NF-kappaB signaling pathway in chondrocytes in vitro. Eur J Pharmacol 636: 181-188, 2010.

33. Hagiwara S, Iwasaka H, Hidaka S, Hasegawa A and Noguchi T: Neutrophil elastase inhibitor (sivelestat) reduces the levels of inflammatory mediators by inhibiting NF-kB. Inflamm Res 58: 198-203, 2009

34. Cheng M, Liu H, Zhang D, Liu Y, Wang C, Liu F and Chen J: HMGB1 enhances the AGE-induced expression of CTGF and TGF- $\beta$ via RAGE-dependent signaling in renal tubular epithelial cells. Am J Nephrol 41: 257-266, 2015.

35. Štros M, Polanská E, Kučírek M and Pospíšilová S: Histone H1 differentially inhibits DNA bending by reduced and oxidized HMGB1 protein. PLoS One 10: e0138774, 2015.

36. Palone F, Vitali R, Cucchiara S, Pierdomenico M, Negroni A, Aloi M, Nuti F, Felice C, Armuzzi A and Stronati L: Role of HMGB1 as a suitable biomarker of subclinical intestinal inflammation and mucosal healing in patients with inflammatory bowel disease. Inflamm Bowel Dis 20: 1448-1457, 2014.

37. Wang J, Tochio N, Takeuchi A, Uewaki J, Kobayashi N and Tate S: Redox-sensitive structural change in the A-domain of HMGB1 and its implication for the binding to cisplatin modified DNA. Biochem Biophys Res Commun 441: 701-706, 2013.

38. Lee W, Ku SK, Na DH and Bae JS: Anti-Inflammatory effects of lysozyme against HMGB1 in human endothelial cells and in mice. Inflammation 38: 1911-1924, 2015. 